\title{
Linking Past and Present: John Dewey and Assessment for Learning
}

\author{
Sharen Kucey \\ Aspen View Public Schools \\ Jim Parsons \\ University of Alberta
}

\begin{abstract}
The purpose of this paper is to explore the principles of Assessment for Learning (AFL) in light of John Dewey's writing about the purpose and possibility of education. In this paper, we compare Dewey's ideas to the goals of assessment for learning (AFL)-a practice emerging globally and, more locally, moved forward by the Alberta Initiative for School Improvement (AISI) program. We believe the principles behind Dewey's educational philosophy are congruent with fundamental principles of AFL. In this paper, we attempt to explicate key intersections between Dewey's teachings and AFL. We review AFL strategies and the foundational philosophy of AFL in an attempt to reveal its connection points to Dewey's educational philosophy. Specifically, we will outline seven AFL strategies and compare these to insights put forth in Dewey's work. Although there is far from adequate space to consider all the matches of Dewey's philosophy and the core principles of Assessment for Learning, we hope our quest for initial commonality might provide curriculum insight for those now working these new pedagogical activities.
\end{abstract}

We are like people looking for something they have in their hands all the time; we're looking in all directions except at the thing we want, which is probably why we haven't found it. (Plato, 380BC)

As the $21 \mathrm{st}$ century unfolds, societal changes affect communication, demographics, personal values, and the labour market. Today's schools and learners can no longer be satisfied with specific career training from the past, because it is difficult to imagine what careers will even exist in the future. Furthermore, past pedagogies that called for an uncritical acceptance of hierarchy, order, and tradition seem to fold in the shifting winds of transformation. Knowledge is the driver in the global economy and, ultimately, educational institutions must ensure that students have the skills needed to succeed. This view is supported by the Government of Alberta's Inspiring Education report (2010): 
Today's generation has seen the rise of knowledge as the key resource of the world's economy. In the future, Alberta's economy will be even more knowledge-based, diverse and grounded in value-added industries. As never before, the next generation will need to be innovative, creative, and skilled at managing knowledge as a resource. (p. 4)

Although the Alberta Government endorses this statement, curriculum policy makers must look ahead, as best they can, and wonder what assortment of knowledge and skills should be part of our children's school life. Indeed, we have accepted some content and skills most of us seem satisfied with - for now: these include personalization in instruction based upon our acceptance that children differ and these differences matter to their learning, the need for critical and creative thinking, and a belief that career adaptability will be increasingly important. This cluster of content has often been dubbed " $21{ }^{\text {st }}$ Century Skills." Still, because change is ever ubiquitous and present, we can never be certain that any specific content can be carried forth successfully through time. And educators continue to argue what this knowledge and these skills look like and how they might best be taught. Where does that put Alberta schools? How successful are they?

One thing we know: Although Alberta is recognized as a world leader in education, success is marginalized by the fact that only $78.6 \%$ of students graduated in 2005-2006 (Government of Alberta, 2009). Without uttering a word, these statistics question the relevance of the existing curriculum in relation to student engagement. From a historical context, each decade is subject to societal demands our educational system is expected to match. But decade after decade, our education system falls short of transformation. This fact begs us to ask at least two crucial questions: Is transformation ever possible? How might an education system hope to gain discretionary wisdom in the face of such dynamic change?

A second thing we know: The pendulum of educational philosophy has swung back and forth between traditional and progressive, between new and old, and between radical and conservative. New theories replaced those that didn't work, only to eventually be discarded. This cycle of in and out should not be surprising. As Dewey (1938/1997) stated, "Mankind likes to think in terms of extreme opposites. It is given to formulating its beliefs in terms of Either-Or, between which it recognizes no intermediate possibilities.... Educational philosophy is no exception" (Chapter 1, para. 1).

A third thing we know: By tradition and contractual agreement, educators are required to teach the skills students need to achieve future success. Most of the skills we are familiar with mirror the needs of previous decades, but some like cursive writing have faded. But goal setting, knowing right from wrong, working with others, and the resiliency to learn from mistakes seem as crucial today as when Canada was a new nation. Today's $21^{\text {st }}$ century children still need to learn to be creative, to inquire, and to be resourceful. These skills promise to be as important as literacy and numeracy.

Finally, we know a fourth thing: Despite an accepted need, educators resist change. This resistance is especially true at the high school level for three 
reasons: (1) the educational paradigm is heavily focused on a narrow definition of academics; (2) teachers' capacity for relaying these skills has not been professionally developed; and (3) the systemic structural supports for school improvement (a focus on content-based summative examinations) are not in line with current trends toward formative assessment and away from heavy summative assessment. We seem to have missed Eisner's (2002) point that "the function of schooling is not to enable students to do better in school. The function of schooling is to enable students to do better in life" (p. 369).

In the midst of such threatening newness, is it possible we might be working too hard to find a new educational philosophy? Obviously, our question is rhetorical. We believe it might be wise to stop the educational pendulum at midswing and look to the past for answers. We also believe Dewey's ideas offer us an opportunity to think critically. In fact, we believe Dewey would be exceedingly pleased with the philosophical direction of a number of emergent pedagogies and the promises these bring to furthering democratic citizenship. Specifically, Dewey's philosophy allows us to see similarities between what he promoted and the goals of today's emergent, learner-centered pedagogies.

In this paper, we compare Dewey's ideas to the goals of assessment for learning (AFL) - a practice emerging globally and, more locally, moved forward by the Alberta Initiative for School Improvement (AISI) program. We believe the principles behind Dewey's educational philosophy are congruent with fundamental principles of AFL. These principles do not appear in the bold type of the extrinsic curriculum but reside, intrinsically, in the spaces between words and concepts such as student engagement, citizenship, creativity, responsibility, and communication. They challenge the pedagogy of teaching, the role of the teacher, the sociology of the classroom, and the role of the student. The purpose of this paper, therefore, is to attempt to explicate key intersections between Dewey's teachings and AFL.

\section{Dewey's Educational Philosophy}

We believe Dewey set the groundwork for modern educational practice. For Dewey, democracy and education were interdependent and his philosophy of education was deeply rooted in the power of inquiry. "Modern life means democracy, democracy means freeing intelligence for independent effectiveness - the emancipation of the mind to do its own work" (Dewey, 1903, p. 193). Schon (1992) states that Dewey "devoted his life to the project of overcoming the dualisms that afflict the field of education...the dualisms of thought and action, research and practice, science and common sense, the academy and everyday life" (p. 121).

In Democracy and Education (1916), Dewey used the term "life" to describe a physical entity and as well as to represent both individual and cultural experiences. The continuity of life in a society depends upon communication and sharing common interests and activities: these include the transmission of habits, traditions, and customs from adults to children. Dewey maintained that children must actively participate in their education because "if the pupil has no initiative of his own in this direction, the result is a random groping after what is wanted, and the formation of habits of dependence upon the cues furnished by others" (Chapter 3, para. 6). For this reason, Dewey criticized traditional modes of 
education as too focused on the issues of the past and lacking in process skills. The result of this teaching paradigm is ennui and boredom, where students find learning "so foreign to the situations of life outside the school as to give them no control over the latter" (Dewey, 1938/1997, Chapter 2, para. 4). In short, memorizing content is less worthwhile than learning how to think and grow into self-efficacious citizens.

Dewey (1938/1997) maintained that the unbridled freedom of progressive education was a reaction against educational deficits created by the traditional paradigm and led to an instructional approach that lacked coherence. Educational freedom is not a valuable experience if educational interactions are troublesome. The value of new learning experiences are subjective and depend on the richness of an individual's past experiences. Knowledge builds upon knowledge. Dewey believed an educational philosophy, or plan, was required when deciding content, method of instruction, and discipline. Teachers must logically organize subject matter, interactions, and learning experiences to account for students' experiences, interests, and learning styles. Before a curriculum can be carried out wisely, there must be "a foresight of the consequences of carrying the impulse into execution - a foresight that is impossible without observation, information, and judgement" (Chapter 6, para. 3). Doll (1993) agrees and believes educational activities must relate to prior knowledge, be open to reflection, and inspire further questioning. Thus, one way to determine the worth of an educational experience is to evaluate its effect on students' current understanding and reflect on how it may influence their future actions.

\section{The Principles of Assessment for Learning}

Knowledge of how to assess students has transformed over the last ten years in part due to the research of Black and Wiliam (Chappuis, 2009). Their work did not begin with a theoretical base, but with practice. To better understand how learning worked, they conducted a global comprehensive review of studies from many countries and from all grade and subject areas. They found that students whose teachers used formative assessment achieved two to four grade levels higher on standardized tests. "The gains reported in the studies were among the largest found for any educational intervention" (p. 3). To promote the concept that assessment must promote learning, and to avoid confusion around the language of AFL, Black (2004) published a precise but detailed definition of what can be described as assessment for learning.

Assessment for learning is any assessment for which the first priority in its design and practice is to serve the purpose of promoting pupils' learning. It thus differs from assessment designed primarily to serve the purposes of accountability, or of ranking, or of certifying competence. An assessment activity can help learning if it provides information to be used as feedback, by teachers and by their pupils in assessing themselves and each other, to modify the teaching and learning activities in which they are engaged. Such assessment becomes 'formative assessment' when the evidence is actually used to adapt the teaching work to meet learning needs. (pp. 2-3) 
Such a language of assessment has the potential to answer the age-old questions Huebner (1966) posed: "What can go on in the classroom?" and "How can this activity be valued?" (p. 14). Assessment for learning, when used freely as an on-going process of discourse between teacher and student, values the ethical and aesthetic aspects of education. It is a respectful and considerate way for teachers to gain a shared understanding of individual students and work with them to shape their learning. It can "heighten student significance" (p. 25).

Perhaps AFL seems more emergent than it truly is; because educators have been considering the usefulness of the principles of formative evaluation for a long time. For example, Sadler (1989), as quoted by Chappuis (2009), suggested that formative assessment would be even more effective if students held a "concept of quality roughly similar to that of the teacher," were able to monitor their own work as it evolved, and had a variety of learning options to choose from (p. 10). Chappuis restructured these conditions as organizing questions and developed an AFL framework that outlined seven strategies of assessment for learning practices that focused on the needs of the learner. These seven strategies of assessment, built around key questions, included:

\section{Where Am I Going?}

1. Provide students with clear and understandable vision of the learning target.

2. Use examples and models of weak and strong work.

Where Am I Now?

3. Offer regular descriptive feedback.

4. Teach students to self-assess and set goals.

\section{How Can I Close the Gap?}

5. Design lessons to focus on one learning target or aspect of quality at one time.

6. Teach students focused revision.

7. Engage students in self-reflection, and let them keep track and share their learning.

In the remainder of this paper, we will consider more closely these strategies and the foundational philosophy of AFL in an attempt to reveal its connection points to Dewey's educational philosophy. Specifically, we will outline these strategies and compare them to insights put forth in Dewey's work. Although there is far from adequate space to consider the matches of Dewey's philosophy and the core principles of Assessment for Learning, the quest for initial commonality might provide curriculum insight for those now working these new pedagogical activities.

\section{Where Am I Going?}

\section{Strategies 1 and 2: Defining Learning Targets and Providing Exemplars}

These first two strategies allow students to develop an understanding of what they will be learning and enable effective feedback at later stages. Teachers 
determine the learning targets based on curricular learner outcomes and communicate these targets in language easily understood by the student. Students, shown examples of both strong and weak work, are provided visual representations of the criteria and the levels of quality required to achieve the outcomes. A clear understanding of the purpose behind of an action can be, in itself, motivating.

As a pre-cursor to self-assessment, teachers encourage students to use scoring guides, or rubrics, to evaluate exemplars before they begin a project or activity. "Many research studies focus on the positive effects of sharing the scoring rubric with students in advance of completing the assessment task, especially for lower achieving students" (Chappuis, 2009, p. 28). Teachers realize that student involvement in the design of these rubrics increases students' understanding of the criterion and leads to more polished work. Feedback is most effective if students are engaged in their learning and sufficient time given for students to compare their work to the exemplars and rubrics.

\section{Heading in the Right Direction-According to Dewey}

These first two strategies match Dewey's philosophy. Dewey (1938/1997) believed that a major deficit in the traditional educational system was the "failure to secure the active cooperation of the pupil in construction of the purposes involved in his studying" (Chapter 6, para. 1). As educators, we are bound by the curriculum, but many choices given within that curriculum provide opportunities to vary the content studied or the process by which the students represent their learning. Teachers who practice AFL are transparent in their motives and goals, because they realize the benefit such transparency has on student motivation. "If interest is aroused, we begin to participate" (Dewey, 1916, Chapter 5, para, 7). Teachers who allow students to set their own directions empower them; and, "such freedom is in turn identical with self-control; for the formation of purposes and the organization of means to execute them are the work of intelligence" (Chapter 6, para.1). To realize that students can accomplish more when they control their own learning, teachers need to relinquish control of the old teacher-learner paradigm.

\section{Where Am I Now?}

\section{Strategy 3 and 4: Regular Descriptive Feedback and Self-Assessment and Goal}

\section{Setting}

Descriptive feedback, either verbal or written, is an ongoing process. For Chappuis (2009), quality feedback has the following characteristics: (1) it directs attention to the learning intended, focusing on strengths and providing information for improvement; (2) it occurs during learn while there is still time to make corrections; (3) it directly addresses partial understanding; (4) it does not provide the student with answers; and (5) it takes into account how much information students can process and act upon at a given time. This AFL strategy provides opportunities for students to evaluate where they are in the learning process.

The tone of the classroom, embodied within teacher-student relationships and rapport between students themselves, impacts the effectiveness of AFL 
implementation. The purpose of AFL is to enhance student learning, but the learning environment must be psychologically safe to ensure student comfort in the assessment process. The teacher assumes the role of facilitator by modeling self-assessment skills and adjusting instruction based on the learning needs of individual students. In AFL classrooms, teachers and students form learning partnerships where students are empowered to become active learners. As Eisner (2002) states: "For the student the aim is to recognize what needs attention; for the teacher it is to be in a position to choose a course of pedagogical action" ( $p$. 170).

Gregory, Cameron, and Davies (2000) claim, "when students are involved in self-assessment, they provide themselves with regular and descriptive feedback to guide their learning" (p. 10). Self- assessment allows students to recognize their strengths and areas for improvement and encourages involvement with the curriculum. They also learn how to use teacher feedback, constructive criticism from other students, and self-assessment to identify what they need to work on and to set goals for future learning. Students can identify personal strengths and areas for improvement before handing in their work. They also learn how to interact and offer descriptive feedback to classmates. Self-assessment thus becomes an essential aspect to learning, and struggling students benefit the most from this AFL practice (Black, 2004).

\section{Dewey Points the Way}

Teachers who practice descriptive feedback, self-assessment, and goal-setting appreciate the process of continuous communication. Dewey (1916) noted that "not only is social life identical with communication, but all communication (and hence all genuine social life) is educative" (Chapter 13, para. 13). His point mirrors the AFL principle that authentic communication is a key to transformation and learning. Teachers must know their students' learning abilities, learning styles, social behaviours, and lives because such information is crucial for effective implementation of AFL and organizing essential learning experiences; and, they do well to learn these aspects of students' lives from students themselves. Dewey (1938/1997) understood that "the objects and events be related intellectually to those of earlier experiences, and this means that there be some advance made in conscious articulation of facts and ideas" (Chapter 7, para. 4). He added, "The primary source of social control resides in the very nature of the work done as a social enterprise in which all individuals have an opportunity to contribute and to which all feel a responsibility" (Chapter 4, para. 11).

\section{Closing the Gap}

\section{Strategies 5 and 6: A Focus on Specific Learning Targets and on Revision}

Formative assessment enables the teacher and student to determine the rate and quality of learning that has taken place. At this point in the AFL continuum, the teacher focuses on students who have partial understandings of the outcomes or lack the skills needed to proceed to the next level of learning. The premise of Strategy 5 is to centre the teacher's attention on a particular concept or skill that needs revision instead of addressing many skills at once. Mechanisms, such as 
scaffolding and differentiated instruction, provide alternative activities that can be shaped to learning styles and levels of difficulty. The choice of content, process, and product (summative assessment) might also vary. Focused revision encourages students to take ownership of their work and to re-work and make corrections based on one criterion at a time. The teaching goal is to help students achieve success. The chance to practice and improve work encourages peer interaction, resiliency, and confidence.

\section{Strategy 7: Self-Reflection}

Self-reflection encourages students to consider a collection of work as evidence of learning, identify their strengths, and feel in control of the circumstances that led to success. Based on clear learning targets, students compare previous and current knowledge. Both previous and current knowledge serve as evidence of learners' achievements and growth. Reflection can also include communicating and sharing what students know to peers, parents, or teachers. By reflecting on their learning, students deepen their understanding (Chappuis, 2009).

\section{Dewey Builds a Bridge}

Central to the AFL process is that the teacher remember that the intellectual growth of the learner is the ultimate goal. "The aim as a foreseen end gives direction to the activity ... it influences the steps taken to reach the end" (Dewey, 1916, Chapter 8, para.5). Reflection is an intellectual activity that substantiates practice, both for students and teachers. van Manen (1995) quotes Dewey by saying, "reflective thinking is important not only as a tool for teaching, but also as an aim for education since it enables us to know what we are about when we act" (p. 33). To change a belief is directly related to the ability to reflect on one's practice. Dewey believed such foresight functions in three ways: (1) it involves careful observations of the conditions to ensure that the means are available to reach the end; (2) it suggests a proper sequence in the use of the means; and (3) it makes a choice of alternatives available. The future success of students depends, in part, on their school experiences. Dewey believed the responsibility of the school and teachers was to "balance the various elements in the social environment, and to see to it that each individual gets an opportunity to escape from the limitations of the social group in which he was born, and come into contact with a broader environment (Chapter 22, para. 2).

\section{Conclusion}

We believe Dewey's ideas set the groundwork for educational practice and the good educational thinking that has reemerged into pedagogies currently being used with great success in Alberta schools. Much of Dewey's educational philosophy focused on the relevance of teaching to the actual lived experiences of the student. This principle remains alive in AFL, as well as a number of other extant pedagogies teachers currently use.

We believe that assessment for learning does not represent an end, but the beginning of an educational philosophy that works to democratize education. As an AISI Learning Coach working for a school district in northern Alberta, Sharen has had opportunities to instruct teachers in the practice of AFL and has watched 
remarkable changes occur in their teaching and the schools in which they work. As a professor in the Faculty of Education at the University of Alberta, Jim has seen the transformations that AFL has had on the insights and actions on longserving Alberta teachers. Classroom doors that have remained closed for decades are slowly opening. Students are more actively involved in the construction and assessment of their own learning, and rooms are alive with the active excitement of student learning. There are fewer classroom 'discipline' problems and more effective teacher-student and student-student relationships. Who can say how these transformed relationships might impact future democratic citizenshipcertainly a societal goal Dewey considered worthy of school curriculum.

Assessment for learning is changing the structure of the classrooms. Teachers who once lectured are stepping away from the front of their classrooms and working beside and with learners: these teachers are building and becoming active parts of a classroom learning community. Communication, peer interaction, and shared experiences are becoming, as Dewey foresaw, a basis for democratic thinking and powerful individual learning. Students in Alberta are benefitting in powerful ways. Dewey, in his wisdom, believed such knowledge would transform society. Although we're less knowledgeable about the whole of society, our experience tells us that AFL is positively changing the lives of students and teachers in the schools we know.

\section{References}

Black, P. (2004). The nature and value of formative assessment for learning. Unpublished manuscript, Educational Testing Service, Princeton, NJ. Retrieved from http://74.125.155.132/scholar?q=cache:RzppkZG-

WasJ:scholar.google.com/+The+Naure+and+value + of + formative + assessment + for + learning + a uthor:black\&hl=en\&as sdt=2000

Chappuis, J. (2009). Seven strategies for assessment of learning. Boston, MA: Pearson.

Dewey, J. (1903). Democracy in education. The Elementary School Teacher, 4(4), 193-204.

Dewey, J. (1916). Democracy and education: an introduction to the philosophy of education. Retrieved from http://www.ilt.columbia.edu/publications/dewey.html

Dewey, J. (1938/1997). Experience and education. In A. Hall-Quest (Ed.), The Kappa Delta Pi lecture series. Retrieved from http://gyanpedia.in/tft/Resources/books/dewey2.pdf

Doll, W. E. (1993). The four r's - an alternative to the Tyler rationale. In W. E. Doll, A PostModern Perspective on Curriculum (pp. 174-183). New York, NY: Teachers College.

Eisner, E. (2002). The centrality of curriculum and the function of standards. Arts and creation of the mind (pp. 148-176). Retrieved http://site.ebary.com//lib/ualberta/Doc?id=10170753\&pp=163

Government of Alberta, Alberta Education. (2009). Your key to success: administrator's guide to raising Alberta's high school completion rate. Retrieved from http://education.alberta.ca/media/900551/promising.pdf

Government of Alberta, Alberta Education. (2010). Inspiring education: A dialogue with Albertans. Retrieved from http://www.ispiringeducation.alberta.ca

Gregory, K., Cameron, C., \& Davis, A. (2000). Knowing what counts: setting and using criteria. Merville, British Columbia: Connections.

Heubner, D. (1966). Curricular language and classroom meanings. In J. MacDonald \& R. Leeper (Eds.), Language and Meaning (pp. 8-26). Washington, DC: Association for Supervision and Curriculum Development.

Schon, D.A. (1992). The theory of inquiry: Dewey's legacy to education. Curriculum Inquiry, 22(2), 119-139. 
van Manen, M. (1995). On the epistemology of reflective practice. Teachers and Teaching: Theory and Practice, 1(1), 33-49.

Sharen Kucey is an AISI Coordinator and Instructional Coach for the Aspen View School Division, Athabasca, Alberta.

Jim Parsons is a Professor, Department of Secondary Education, University of Alberta, Edmonton, Alberta. 